\title{
Effects of Buffalo and Cow Milk Mixtures Enriched With Sodium Caseinates on the Physicochemical, Rheological and Sensory Properties of a Stirred Yogurt Product
}

\author{
Dimitris Petridis ${ }^{1}$, Georgia Dimitreli ${ }^{1}$, Kalliopi Vlahvei ${ }^{1} \&$ Christodoulos Deligeorgakis ${ }^{1}$ \\ ${ }^{1}$ Department of Food Technology, Alexander Technological Educational Institute, Thessaloniki, Greece \\ Correspondence: Dimitris Petridis, Department of Food Technology, Alexander Technological Educational \\ Institute, P.O. Box 14561, GR 54101, Thessaloniki, Greece. Tel: 30-231-001-3917. E-mail: \\ petridis@food.teithe.gr
}

Received: June 30, 2014 Accepted: July 31, 2014 Online Published: August 6, 2014

doi:10.5539/jfr.v3n6p54 URL: http://dx.doi.org/10.5539/jfr.v3n6p54

\begin{abstract}
The physicochemical, rheological and sensory (objective and hedonic) properties of stirred yogurt made from buffalo and cow milk mixtures enriched with Sodium Caseinates (SCN) were evaluated. Five different milk mixtures (buffalo:cow; 0:100, 25:75, 50:50, 75:25, 100:0) with or without the addition of $1 \% \mathrm{SCN}$ were fermented so as to produce 10 different yogurt samples. According to the results, SCN addition increased the brightness $\left(\mathrm{L}^{*}\right)$, the elastic behavior, the viscosity (instrumental and sensory) and the flow behavior index (n), while it reduced the yellow color intensity $\left(b^{*}\right)$ of yogurt samples. Addition of milk affected significantly all the instrumental variables apart from the green color intensity $\left(\mathrm{a}^{*}\right)$ and so happened but sparsely with the interactive effects between milk mixture and SCN addition. Redundancy analysis was proved a successful tool to elucidate the complex physicochemical, rheological and sensory profile of the stirred yogurt samples. Loss tanget $(\tan \delta)$ and $\mathrm{b}^{*}$ were indicative for high cow milk concentrations and the rest of attributes fashion with high buffalo milk concentrations, apart from $\mathrm{n}$ which favored samples with high cow milk enrichment and SCN addition. Panelists prefered adequately a stirred yogurt rich in buffalo milk concentration (75-100\%) and low in cow milk (0-25\%), enriched with SCN, with texture perceived as adequate fatty and viscous.
\end{abstract}

Keywords: buffalo milk, cow milk, stirred yogurt, sodium caseinates, rheological properties, sensory properties, redundancy analysis

\section{Introduction}

Yogurt is a fermented milk product widely consumed around the world. Its popularity has increased in recent times due to its perceived health benefits along with providing to the consumer convenience, taste and wholesomeness attributes. The rise in yoghurt consumption is also related to the choices available in the marketplace including varieties of flavors and textures, packaging innovations, etc (Chandan, 2006). Despite these and other innovations, yogurt can be presented to the consumer in either a gel form (set yogurt) or as a viscous fluid (stirred yogurt) (Robinson, Lucey, \& Tamine, 2006).

The starter culture used for yogurt production consists of two bacteria that live symbiotically, Streptococcus thermophilus and Lactobacillus delbrueckii subsp. bulgaricus (Tamine \& Robinson, 2007). During fermentation, acid production by these two bacteria reduces the high net negative charge in milk to close to no net charge with the approach of the isoelectric point of casein ( $\mathrm{pH}$ 4.6). This allows the approach and aggregation of casein molecules through hydrophobic and electrostatic interactions and the formation of a three dimensional protein network (gel). The denatured whey proteins, resulting from milk heat treatment, become mostly associated with caseins micelles during heat treatment or they do so during the acidification process (they precipitate along with caseins) (Lucey, 2004a). During the cooling procedure, an increase in gel firmness occurs due to the swelling of the casein particles as their hydrophobic interactions weaken with an increase in contact area between particles. Contact between the particles through additional hydrogen bonds or disulphide cross-links between denatured whey proteins and $\kappa$-caseins leads to improved texture (Robinson et al., 2006). For stirred yogurt, structure breakdown takes place just after fermentation. Stirred yogurt can initially be considered as a dispersion of gel particles in serum but re-formation of bonds occurs such that a weak gel network is soon established (Lucey, 
2004a).

Fresh bovine milk is usually the basic material for making yogurt in the Western world, although ovine, caprine or buffalo milks can also be used (Robinson et al., 2006). The milk of various animals differs in composition and produces fermented products and thus yogurt with a characteristic texture and flavor. The milk of various mammals exhibits significant differences in total solids and in fat, mineral and protein content (Chandan, 2006) subsequently affecting on the rheological and textural (instrumental and sensory) properties of the final product. Milk rich is proteins will result in yogurt with increased viscosity, firmness and elasticity due to the higher number of protein interactions and bonds (Sodini, Remeuf, Haddad, \& Corrieu, 2004) among denatured whey proteins and caseins (Lucey \& Singh, 1998). The increase in fat content will result in a creamy mouth-feel (Lucey, 2004b) but also in increased viscosity and firmness in yogurt samples (Sodini et al., 2004). The latter can be attributed to the interactions between the fat globule membrane and the protein matrix. Milk minerals increase its nutritional value and affect the stability and size of milk proteins (Walstra, Wouters, \& Geurts, 2006). Fermentation of the milk of buffalo and sheep produces a smooth texture with increased consistency, while the milk of other animals, like cow, tends to generate a soft gel consistency (Chandan, 2006). The fortification of milk with non-fat solids, like caseinates or whey proteins concentrates, is a way to improve yogurt's consistency or "mouth-feel". Caseinates due to their physical structure are more efficient than whey proteins in increasing yogurt's consistency (Robinson et al., 2006).

The textural and sensory attributes of fermented milk products including yogurt are critically important for the consumer in determining product acceptability (Lucey, 2004a). A few researchers have focussed their study on the factors influencing the rheological (Hanif, Zahoor, Iqbal, Ihsan-ul-haq, \& Arif, 2012) and sensory (Masud, Khalid, Maqsood, \& Bilal, 2010; Hanif et al., 2012; Simanca, Andrade, \& Arteage, 2013) properties of buffalo milk yogurt. Recently Petridis, Dimitreli, Chrysalidou and Akakiadou (2013) evaluated the effect of chemical composition (casein, whey protein and fat content) on the rheological and sensory properties of stirred yogurt made from buffalo milk. A marketable product was derived using a consumer-optimized combination of the three components. The same authors (Dimitreli, Petridis, Akakiadou, \& Chrysalidou, 2014) also studied the combined effect of proteins addition, fat globule size and storage time on the physicochemical, rheological and sensory properties of buffalo milk stirred yogurt.

The aim of the present work was to study the ability of substitution part of the buffalo with cow milk and simultaneously to enrich the milk blend with Sodium Caseinates ( $\mathrm{SCN})$ in the production of stirred yogurt. Substitution of certain amount of buffalo milk can reduces the cost of product. In addition, the aim of this study was to investigate if SCN addition could enhance rheological properties of the final product. Yogurt samples will be rheologically and sensory evaluated, with aim to relate the sensory with the instrumental perception of texture.

\section{Materials and Methods}

\subsection{Materials}

Full-fat buffalo (7.9\%) and cow (3.6\%) milk, which were pasteurized and homogenized (purchased from local dairy), a Direct Vat Set (DVS) starter culture consisting of the microorganisms Streptococcus thermophilus and Lactobacillus delbrueckii subsp. bulgaricus (Jointex X3, Dosi 4; CSL Centro Spermentale, de Latte S.P.A, Zelo Buon Persico, Italy) and SCN (MIPRODAN 30; Arla Food Ingredients, Viby J., Denmark) (moisture $\leq 6 \%$; proteins $88 \%-93.5 \%$; fat $1.5 \%$; ash $4 \%$; lactose $0.3 \%$ ) were used for samples preparation.

\subsection{Preparation of Stirred Yogurt Samples}

Five different milk mixtures (buffalo and cow) were prepared according to the experimental design described in section 2.6. Yogurt samples were made with or without the addition of $1 \% \mathrm{w} / \mathrm{w} \mathrm{SCN}$ into the milk (before heat treatment). After being added to the milk, SCN were dissolved under continuous stirring (Grant GLS400 shaking water-bath; Grant Instruments Ltd, Cambridge, G.B.) for 20 min at $35^{\circ} \mathrm{C}$. The milk with or without the SCN was heated in the shaking water-bath $\left(85^{\circ} \mathrm{C}\right.$ for $\left.15 \mathrm{~min}\right)$, cooled down $\left(42^{\circ} \mathrm{C}\right)$, inoculated with the starter culture (according to the instructions of the manufacturer), placed in the shaking water-bath $\left(42{ }^{\circ} \mathrm{C}\right)$ for 5 min and incubated (Cooled Incubator Series 8000, Termaks AS, Bergen, Norway) at $42{ }^{\circ} \mathrm{C}$ until the $\mathrm{pH}$ dropped to 4.6. At the end of the fermentation process yogurt samples were treated (cooled and mixed) as described by Petridis et al. (2013). Stirred yogurt was then cooled at $4{ }^{\circ} \mathrm{C}$ and stored in the refrigerator for 1 day before testing. Milk formulations and yogurt samples were handled and stored using sterilized glass containers.

\subsection{Physicochemical Analysis}

The Dry Matter (DM) content of the samples was determined by drying at $102 \pm 1{ }^{\circ} \mathrm{C}$ to a constant weight (IDF, 
1991) and the fat content by the Gerber method (ISO, 1976). The Non Fat Dry Matter (NFDM) content was also calculated (NBDM $=$ DM \% - Fat \%). The $\mathrm{pH}$ of yogurt samples was measured using a GP353 ATC pH METER (EDT Instruments, Kent U.K.). Their acidity was expressed as lactic acid concentration (\% w/w) according to AOAC (2002). For the determination of the color with the CIE Lab scale, a tristimulus colorimeter Micro Color LMC (Dr. Bruno Lange GmbH, Dusseldorf, Germany) was used. The three color components determined (according to the Hunter Lab format) were $\mathrm{L}^{*}$ (brightness), $\mathrm{a}^{*}$ ( + red to - green component) and $\mathrm{b}^{*}$ ( + yellow to - blue component). All measurements were conducted in triplicate.

\subsection{Instrumental Design}

The rheological behavior of stirred yogurt was evaluated by using a small deformation test so as to study the viscoelastic behavior of the samples and by the determination of the apparent viscosity of the samples in order to correlate the sensory perception of texture with the rheological properties related to shearing, imitating this way the consumption of stirred yogurt from the consumers. All rheological measurements were made in triplicate.

\subsubsection{Apparent Viscosity}

The determination of the apparent viscosity was made by placing the samples inside the sample vessel of the custom built pneumatic tube rheometer coded TR-1 Rheometer (A.T.E.I. of Thessaloniki, Greece) (Xu \& Raphaelides, 1998; Dimitreli \& Thomareis, 2004) under continuous stirring $(50 \mathrm{rpm})$ at $20{ }^{\circ} \mathrm{C}$. The instrument has already been used for the evaluation of the rheological behavior of stirred buffalo milk yogurt (Petridis et al., 2013; Dimitreli et al., 2014).

For the rheological measurements two capillary tubes with different dimensions, attached to the bottom of the sample vessel were used. The first one had an inner diameter of $2.050 \mathrm{~mm}$ and a length of $30 \mathrm{~mm}$ and the second had dimensions of 0.975 and $35 \mathrm{~mm}$, respectively.

The flow behavior index (n) values were calculated from the flow curves of the samples that is the apparent viscosity as a function of the shear rate.

\subsubsection{Viscoelastic Behavior}

Dynamic Analysis was applied to the yogurt samples using a DMA rheometer (Bohlin C-VOR 150, Malvern Instruments, Ltd, Worcestershire, UK) equipped with a $40 \mathrm{~mm}$ diameter plate and a $4^{\circ}$ stainless steel cone. A Peltier plate system $\left(-30\right.$ to $\left.+180{ }^{\circ} \mathrm{C}\right)$ was used for temperature control. Rheological measurements were performed at $20^{\circ} \mathrm{C}$.

A frequency sweep from 0.01 to $10 \mathrm{~Hz}$ was applied at strain deformation within the linear viscoelastic region $\left(1.304 \times 10^{-5}\right)$ previously determined by an amplitude test, so as to determine the elastic $\left(\mathrm{G}^{\prime}\right)$ and viscous $\left(\mathrm{G}^{\prime \prime}\right)$ moduli as well as the loss tangent $(\tan \delta)$ of the samples. The rheological properties $\left(\mathrm{G}^{\prime}\right.$ and $\left.\tan \delta\right)$ at $1 \mathrm{~Hz}$ frequency were used for the statistical analysis.

\subsection{Sensory Analysis}

Objective sensory attributes were performed using a thoroughly trained panel comprising of members of the School's staff, aged 30-50 years, plus six research students. These had been selected from a larger pool of initial volunteers, about four years ago, and were initially trained on the assessment of milk products using different milk formulations with a characteristic texture; these panelists were screened, the outliers rejected from the panel and a pool of trained milk testers was established. These panelists were trained as a group and have already performed a large number of sessions on milk mixtures for the previous works of this group. Their performance has always been evaluated prior to formal sessions, using commercial milk products, and known recipes giving extremes (i.e. very viscous $v s$. very liquid-like milk product).

Sensory properties of yogurt samples were evaluated after being set to equilibrium at $20{ }^{\circ} \mathrm{C}$, gently mixed, placed in special cups (approximately $20 \mathrm{~g}$ ) arranged in white plastic dishes and presented to panelists hosted in sensory booths. The order of assessment was randomized within each session. Bottled water and toast were provided to clean the palate between samples in both objective and hedonic tests.

The sensory chamber consisted of purpose-built sensory booths $(2 \times 5$ booths $)$ in a dedicated, isolated noise-free room of controlled temperature and lighting. Individual booths were supplied with their own water tap and three lighting modes (white, green, and red), allowing each tester isolation and convenience in performing his/her tasks. Samples were served from a sliding door in the front of each booth. The principles laid down by EA-4 supplement to ISO17025 concerning quality assurance for sensory testing laboratories adhered to throughout the experiments.

Fifteen panelists were used twice $(15 \times 2$ runs) to assess the perception of intensity of the following attributes: 
- Odor as the typical aroma of the product ascribed mainly to acetaldehyde.

- White color intensity as the brightness.

- Acidity as the intensity of the acid flavor in the mouth.

- Fattiness as the fatty feeling in the mouth and gum.

- Viscosity as the perceived degree of thickness when yogurt was squeezed between tongue and the roof of the mouth and sheared during the back and forth motions of the tongue.

The same attributes were assessed for the perception of acceptability (hedonic evaluation) by new panelists who had not previous experience on sensory trials such as students from the first two semesters. This group was taught all the definitions of the attributes in order to become conditioned with the subject before to rate the acceptability of the aforesaid attributes. The hedonic assessment was conducted three times using 45 panelists.

The intensity of a sensory attribute, either objective or hedonic, was recorded using a $0-15 \mathrm{~cm}$ unstructured scale starting with the perception 'not at all' intense on the left part of the line $(0 \mathrm{~cm})$ and ending to the right part $(15$ $\mathrm{cm}$ ) with the perception 'very' intense of the attribute. Hedonic intensity of an attribute was assessed as not at all acceptable attribute to very acceptable.

Dotplot graphs were employed to detect potential outliers among objective sensory scores per treatment. Adjusted mean score for each attribute was calculated from the 10 samples of each run.

\subsection{Experimental Design}

The experimental design included five increasing concentrations of buffalo milk (BM) in a parallel decreasing order of cow milk (CM) addition according to the scheme shown in Table 1.

Table 1. The five different milk mixtures of buffalo (BM) and cow (CM) milk

\begin{tabular}{llllll}
\hline Milk & Mixtures & & & \\
\hline BM (\%) & 0 & 25 & 50 & 75 & 100 \\
CM (\%) & 100 & 75 & 50 & 25 & 0 \\
\hline
\end{tabular}

The above 5 treatments were doubled as to incorporate the effect of SCN addition (1) or none (0).

For reasons of simplicity the milk blends and SCN addition were abbreviated on the base of buffalo interest of the study as follows: BM_0, BM_25, BM_50, BM_75, BM_100, and SCN_0, SCN_1, respectively.

The resulted 10 treatments (milk mixture $\times$ SCN addition) were sensorily assessed according to the particular plain 11.16 as described by Cochran and Cox (1957) with the following parameters:

$\mathrm{t}=10$ treatments, $\mathrm{b}=15$ panelists, $\mathrm{k}=4$ treatments evaluated per panelist, $\mathrm{r}=6$ sampling units per treatment, $\lambda=2$ pairs of similar treatment encounters in the design.

Variables from different scientific origin, such as rheological, colorimetric and chemical, were also measured in the same samples in order, in joint with the sensory attributes, to produce a spherical view of a new product with particular texture characteristics and estimate for product blending optimization.

\subsection{Data Analysis}

Data were treated using a fixed two-way full factorial analysis of variance (milk mixture, casein addition) and statistically significant effects among main and interaction levels were further examined adopting the comparison of the $95 \%$ confidence limits of level means. Means whose confidence intervals do not overlap differ significantly.

The main factor effects on the multi-oriented variables were also examined employing the redundancy analysis as recently upgraded by ter Braak and Smilauer (2012). The two factors were considered as the independent variable set (five milk concentrations plus two SCN levels) and suitably modified to a nominal variable with seven levels. All the attributes, sensory objective, physicochemical and rheological, were treated as the dependent set, thus potential factor effects and interrelationships among variables can be detected by regressing the attribute set on the factor variable. In other words, the dependent variables are regressed against the independent factorial levels and afterwards their fitted responses are used to build a canonical principal component triplet including the two variables set and the distribution of the interactive sampling units. The same 
procedure was repeated regarding solely as dependent set the hedonic variables.

Statistics were performed using the MINITAB 16.0 and CANOCO 5.0 software.

\section{Results and Discussion}

\subsection{Instrumental Properties}

The instrumental variable profile as arranged by the factorial levels is presented in Table 2. Addition of SCN in the samples increased the NFDM $(9.46>8.37)$ and $\mathrm{n}(0.88>0.73)$ but reduced the mean values of $\mathrm{b}^{*}(2.44<3.00)$ and $\tan \delta(0.85<0.90)$. Milk blending affected significantly all the instrumental variables apart from $\mathrm{a}^{*}$ and so happened but sparsely with the interactive effects between milk mixture and SCN addition.

The particular performance of each attribute is vividly described in Figures 1 and 2. Due to the high number of variables involved and their different measurement units, attributes were standardized to a range of -1.0 to +1.0 standard deviations.

Under this transformation regime as it can be seen in Figure 1, milk fat increased steadily with buffalo milk addition, L* increased sharply up to $50 \%$ buffalo concentration enriched with $\mathrm{SCN}$ after which the increase relents. The $b^{*}$ color component declined persistently with buffalo milk enrichment, however this decline started from the middle and lower level of $b^{*}$ standardized values (Axis Y) when SCN were added resulting ultimately in a significant effect of SCN addition (consult also Table 1). The increase in $\mathrm{L}^{*}$ with increasing buffalo concentration can be attributed to the increased protein and fat content of buffalo milk when compared to cow milk (C. D. Khedkar, G. D. Khedkar, Patil, \& Kalyankar, 2003).

Table 2. Mean values ( \pm SE below) of the physicochemical and rheological profile as tabulated by the main and interaction effects of milk blending and Sodium Caseinates $(\mathrm{SCN})$ addition. Bold numbers indicate significant effects of SCN at 0.05 probability level

\begin{tabular}{|c|c|c|c|c|c|c|c|c|c|c|}
\hline \multirow[b]{2}{*}{ Treatment } & \multicolumn{3}{|c|}{ Colorimetric variables } & \multicolumn{2}{|c|}{ Chemical variables } & \multicolumn{5}{|c|}{ Rheological variables } \\
\hline & $\mathbf{L}^{*}$ & $a^{*}$ & $\mathbf{b}^{*}$ & Fat (\%) & Acidity (\%) & DM (\%) & NFDM (\%) & $\mathbf{n}$ & $\mathbf{G}^{\prime}(\mathbf{P a})$ & $\tan \delta$ \\
\hline \multirow[t]{2}{*}{$\overline{\text { SCN_0 }}$} & 88.9 & -2.38 & 3 & 5.64 & 0.96 & 14.01 & 8.37 & 0.73 & 227.4 & 0.9 \\
\hline & 0.55 & 0.03 & 0.18 & 0.5 & 0.04 & 0.77 & 0.28 & 0.04 & 25.66 & 0 \\
\hline \multirow[t]{2}{*}{ SCN_1 } & 89.91 & -2.4 & 2.44 & 5.52 & 1.03 & 14.97 & 9.46 & 0.88 & 274.2 & 0.85 \\
\hline & 0.53 & 0.03 & 0.16 & 0.49 & 0.04 & 0.67 & 0.17 & 0.01 & 40.73 & 0.02 \\
\hline \multirow[t]{2}{*}{ BM_O } & 86.98 & -2.4 & 3.45 & 3.56 & 0.83 & 11.53 & 7.98 & 0.87 & 158.3 & 0.91 \\
\hline & 0.26 & 0.06 & 0.21 & 0.02 & 0.03 & 0.42 & 0.44 & 0 & 5.12 & 0 \\
\hline \multirow[t]{2}{*}{ BM_25 } & 88.18 & -2.4 & 2.98 & 4.58 & 0.93 & 13.03 & 8.46 & 0.86 & 180.5 & 0.9 \\
\hline & 0.28 & 0.06 & 0.15 & 0.06 & 0.02 & 0.33 & 0.39 & 0.01 & 6.7 & 0 \\
\hline \multirow[t]{2}{*}{ BM_50 } & 89.93 & -2.38 & 2.78 & 5.43 & 0.98 & 14.24 & 8.81 & 0.79 & 219 & 0.9 \\
\hline & 0.6 & 0.05 & 0.19 & 0.06 & 0.01 & 0.31 & 0.35 & 0.05 & 4.65 & 0.01 \\
\hline \multirow[t]{2}{*}{ BM_75 } & 90.8 & -2.4 & 2.43 & 6.51 & 1.07 & 15.98 & 9.47 & 0.74 & 259 & 0.84 \\
\hline & 0.21 & 0.06 & 0.14 & 0.03 & 0.01 & 0.16 & 0.18 & 0.06 & 11.87 & 0.03 \\
\hline \multirow[t]{2}{*}{ BM_100 } & 91.15 & -2.38 & 1.98 & 7.83 & 1.15 & 17.67 & 9.85 & 0.76 & 437.3 & 0.83 \\
\hline & 0.16 & 0.05 & 0.16 & 0.05 & 0.04 & 0.17 & 0.22 & 0.1 & 40.14 & 0.03 \\
\hline \multirow[t]{2}{*}{$0 \_0$} & 86.55 & -2.4 & 3.8 & 3.59 & 0.77 & 10.81 & 7.22 & 0.87 & 149.5 & 0.92 \\
\hline & 0.05 & 0.1 & 0.1 & 0.01 & 0.02 & 0.04 & 0.05 & 0 & 0.5 & 0 \\
\hline \multirow[t]{2}{*}{$25 \_0$} & 87.7 & -2.4 & 3.2 & 4.68 & 0.9 & 12.46 & 7.78 & 0.84 & 169 & 0.91 \\
\hline & 0.07 & 0.1 & 0.1 & 0.03 & 0.02 & 0.02 & 0.01 & 0 & 1 & 0 \\
\hline \multirow[t]{2}{*}{ 50_0 } & 88.9 & -2.35 & 3.1 & 5.5 & 0.96 & 13.7 & 8.2 & 0.7 & 212 & 0.91 \\
\hline & 0.1 & 0.05 & 0.1 & 0.04 & 0.02 & 0.08 & 0.08 & 0 & 4 & 0 \\
\hline \multirow[t]{2}{*}{$75 \_0$} & 90.45 & -2.4 & 2.65 & 6.55 & 1.06 & 15.71 & 9.16 & 0.64 & 238.5 & 0.89 \\
\hline & 0.05 & 0.1 & 0.05 & 0.05 & 0.01 & 0.05 & 0 & 0 & 1.5 & 0 \\
\hline 1000 & 90.9 & -2.35 & 2.25 & 7.9 & 1.09 & 17.38 & 9.48 & 0.59 & 368 & 0.89 \\
\hline
\end{tabular}




\begin{tabular}{lllllllllll}
\hline \multirow{4}{*}{$0 \_1$} & 0.1 & 0.05 & 0.05 & 0.03 & 0 & 0.02 & 0.02 & 0 & 2 & 0.01 \\
& 87.4 & -2.4 & 3.1 & 3.53 & 0.88 & 12.26 & 8.74 & 0.87 & 167 & 0.9 \\
$25 \_1$ & 0.2 & 0.1 & 0.1 & 0.02 & 0.01 & 0.08 & 0.06 & 0 & 2 & 0 \\
& 88.65 & -2.4 & 2.75 & 4.48 & 0.95 & 13.6 & 9.13 & 0.87 & 192 & 0.9 \\
$50 \_1$ & 0.05 & 0.1 & 0.15 & 0.03 & 0.01 & 0.02 & 0 & 0 & 2 & 0.01 \\
& 90.95 & -2.4 & 2.45 & 5.35 & 1 & 14.77 & 9.42 & 0.87 & 226 & 0.89 \\
$75 \_1$ & 0.15 & 0.1 & 0.05 & 0.1 & 0.01 & 0.1 & 0 & 0 & 4 & 0 \\
& 91.15 & -2.4 & 2.2 & 6.48 & 1.09 & 16.25 & 9.78 & 0.84 & 279.5 & 0.8 \\
$100 \_1$ & 0.15 & 0.1 & 0.1 & 0.02 & 0.01 & 0.05 & 0.07 & 0 & 1.5 & 0 \\
& 91.4 & -2.4 & 1.7 & 7.75 & 1.22 & 17.97 & 10.22 & 0.93 & 506.5 & 0.77 \\
& 0.1 & 0.1 & 0.06 & 0.05 & 0.01 & 0.05 & 0 & 0 & 8.5 & 0.01 \\
\hline
\end{tabular}

The milk blends and SCN addition were abbreviated on the base of buffalo interest of the study as follows: BM_0, BM_25, BM_50, BM_75, BM_100, and SCN_0, SCN_1, respectively; L*, a* and $b^{*}$ : the three components of color; DM: Dry Matter; NFDM: Non Fat Dry Matter; n: Flow behavior index; G': Elastic modulus; $\tan \delta$ : loss tangent.

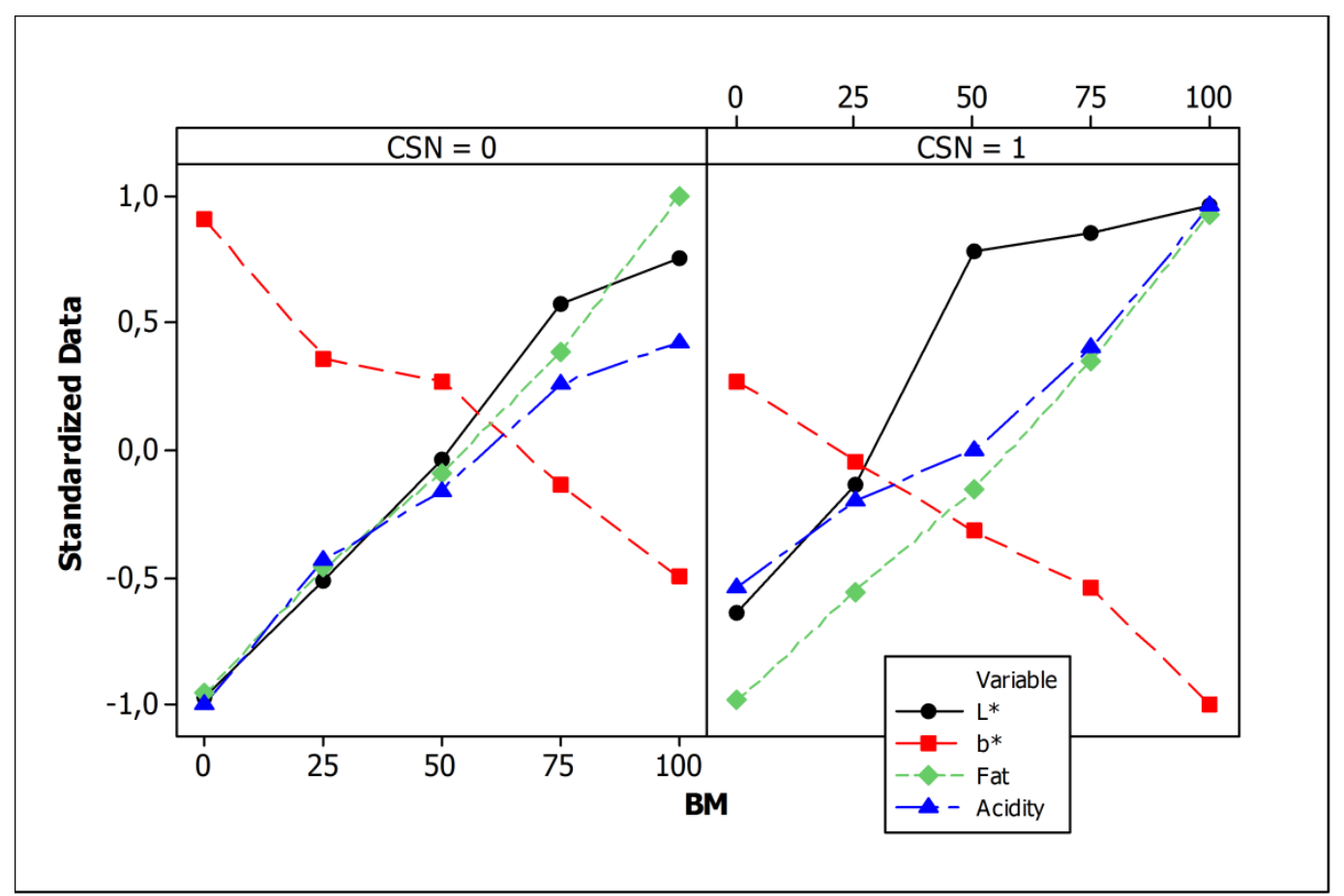

Figure 1. Distibution of standardized attribute means ( $\mathrm{L}^{*}, \mathrm{~b}^{*}$, Fat, Acidity) along with the increasing buffalo milk concentration and addition of Sodium Caseinates ( $\mathrm{SCN}$ ) or none. The milk blends and SCN addition were abbreviated on the base of buffalo interest of the study as follows: BM_0, BM 25, BM 50, BM $\_75$, BM $\_100$, and SCN_0, SCN_1, respectively; L*and b*: the two components of color

The white color of dairy products is due to the light scattering into the casein micelles and fat globules (Walstra et al., 2006). When the number of the scattering particles is increased the white color intensity also increases. Addition of SCN into the milk blends increases even more the $\mathrm{L}^{*}$ values. However, this increase reaches the maximum when the buffalo milk is added into the milk blend in a percentage more than $50 \%$, meaning that the maximum intensity of white color can be achieved in the presence of SCN in a milk blend of buffalo:cow milk 50:50. The decrease in $b^{*}$ value and thus in the yellow color intensity is related to the presence of caseins and fat globules giving rise to a more white color intensity. Furthermore, the increased values of $b^{*}$ with increasing cow milk percentage is due to the increased concentration of carotenoids into the cow milk when compared to buffalo milk (Fox, Guinee, Cogan, \& McSweeney, 2000). 
The pattern of variables, depicted in Figure 2, appears more complicated. DM increased linearly with buffalo milk increment in joint with SCN addition, while the rise of NFDM occured from the uppermost range of the standardized values when SCN were added resulting in a significant main casein effect (Table 1). The addition of SCN into the milk blends increased the level of proteins resulting in increased values of NFDM even at low buffalo milk concentrations. However, the increasing buffalo milk concentration increased the level of both fat and protein content, resulting in a simultaneously increase in DM and NFDM in the absence of SCN.

G' increased curvilinearly showing higher elevation from $75 \%$ to $100 \%$ buffalo milk quantities in joint with SCN addition (Figure 2, Table 1). Responsible for the increase in G' values are caseins. The addition of caseins into the milk system (either as SCN neither with the increasing buffalo milk concentration) increases the possibility of either bigger or more casein clusters being formed during fermentation resulting in increased elasticity of the protein matrix. According to Walstra et al. (2006) there is a power-law relation between the casein concentration and the consistency of the casein-containing systems.

A profound effect of interaction between milk blending and SCN was exerted on the performance of $\tan \delta$ and $\mathrm{n}$. Tan $\delta$ descended slowly when buffalo milk concentration increased but at SCN addition and at $50 \%$ buffalo milk concentration, an abrupt drop of the attribute took place reaching low levels at $100 \%$ full buffalo mixing. An inverse situation stands for the $\mathrm{n}$ which remained stable at all buffalo milk levels enriched with SCN and declined abruptly at concentrations $>25 \%$ free of SCN.

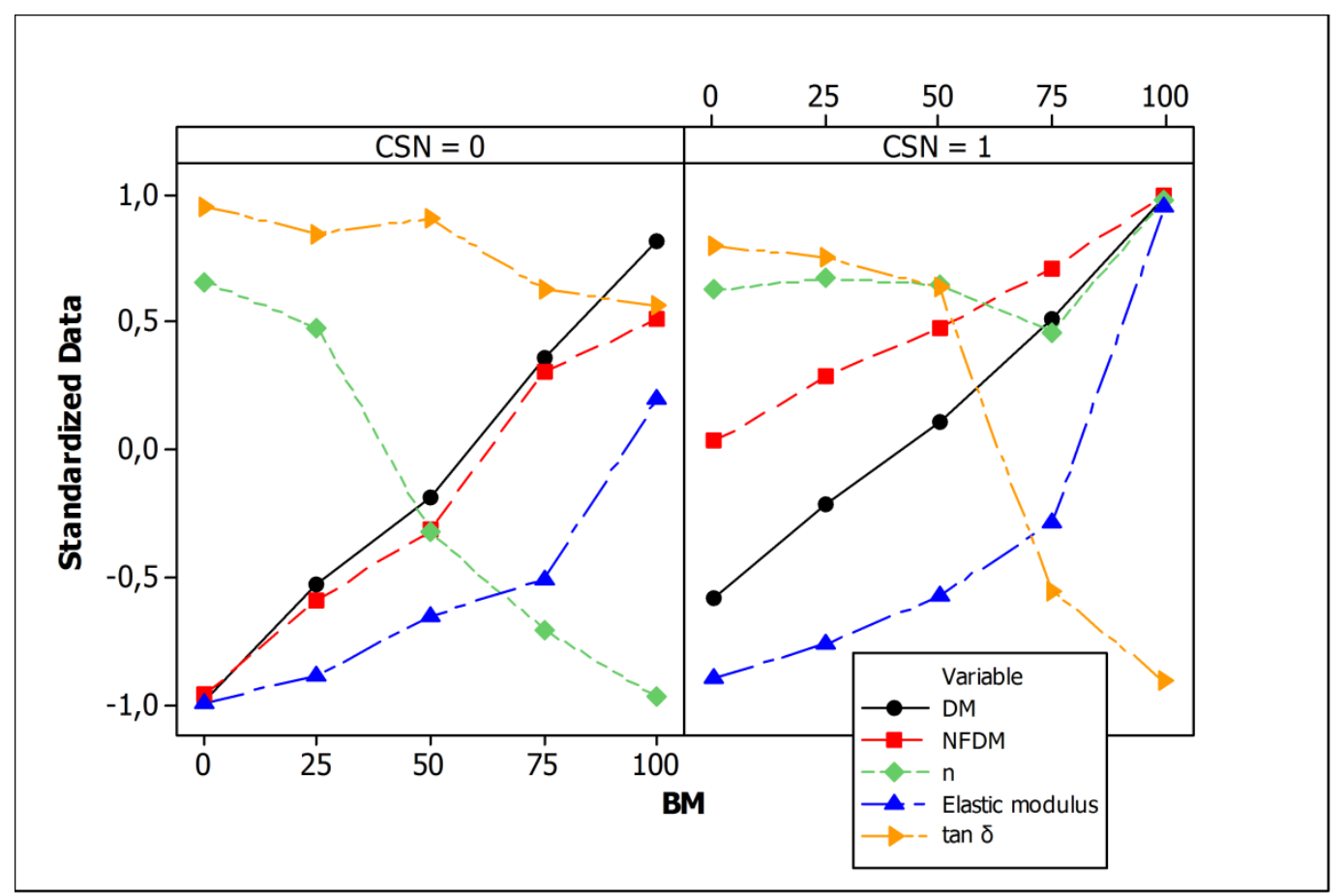

Figure 2. Distribution of standardized attribute means (DM, NFDM, n, Elastic modulus, $\tan \delta$ ), along with the increasing buffalo milk concentration and the addition of Sodium Caseinates (SCN) or none

The milk blends and SCN addition were abbreviated on the base of buffalo interest of the study as follows: BM_0, BM_25, BM_50, BM_75, BM_100, and SCN_0, SCN_1, respectively; DM: Dry Matter; NFDM: Non Fat Dry Matter; n: Flow behavior index; $\tan \delta$ : loss tangent.

The presence of buffalo milk into the milk mixture gives rise to a protein and fat content increase. The increasing protein concentration increases the elasticity of the matrix throughout protein-protein interactions and bonds, decreasing this way the viscous behavior of the samples (decreased values of $\tan \delta$ ). However the presence of buffalo milk fat globules into the yogurt system reinforces its viscous behavior. This can be attributed to their bigger size when compared to cow fat globules (Khedkar et al., 2003), forcing protein strands to be more elongated to surround and occlude them, reducing this way the strength of the protein matrix and thus its elastic character. This is the reason for the slowly decrease in $\tan \delta$ values when buffalo concentration increases in the absence of SCN. However, SCN addition strengthens the role of caseins into the system, resulting in increased 
number of interactions between buffalo proteins and added caseins and thus substantial decrease in the viscous behavior of the system.

The decrease of $\mathrm{n}$ (more intensive pseudoplastic behavior) with increasing buffalo content can be attributed to the solid state most of the buffalo milk fat. According to Khedkar et al. (2003) buffalo milk contains higher proportions of high melting triglycerides than cow milk and as a result it is more solid. The liquid state of milk fat is the cause for the dairy liquid products to exhibit Newtonian behavior, which becomes shear thinning at low temperatures when cold agglutination of fat globules occurs (Walstra et al., 2006). However, the presence of caseins into the milk system alters the rheological behavior of yogurt samples. Pseudoplastic behavior can be said to be the result of the rotation and orientation of the flexible molecules into the direction of the flow. In the case of caseins and their existence as micelles with a compact and circular configuration, the aggregates formed are far from being flexible, exhibiting a tendency towards Newtonian behavior but with increased apparent viscosity (Figure 3 ) owning to their increased hydrodynamic volume.

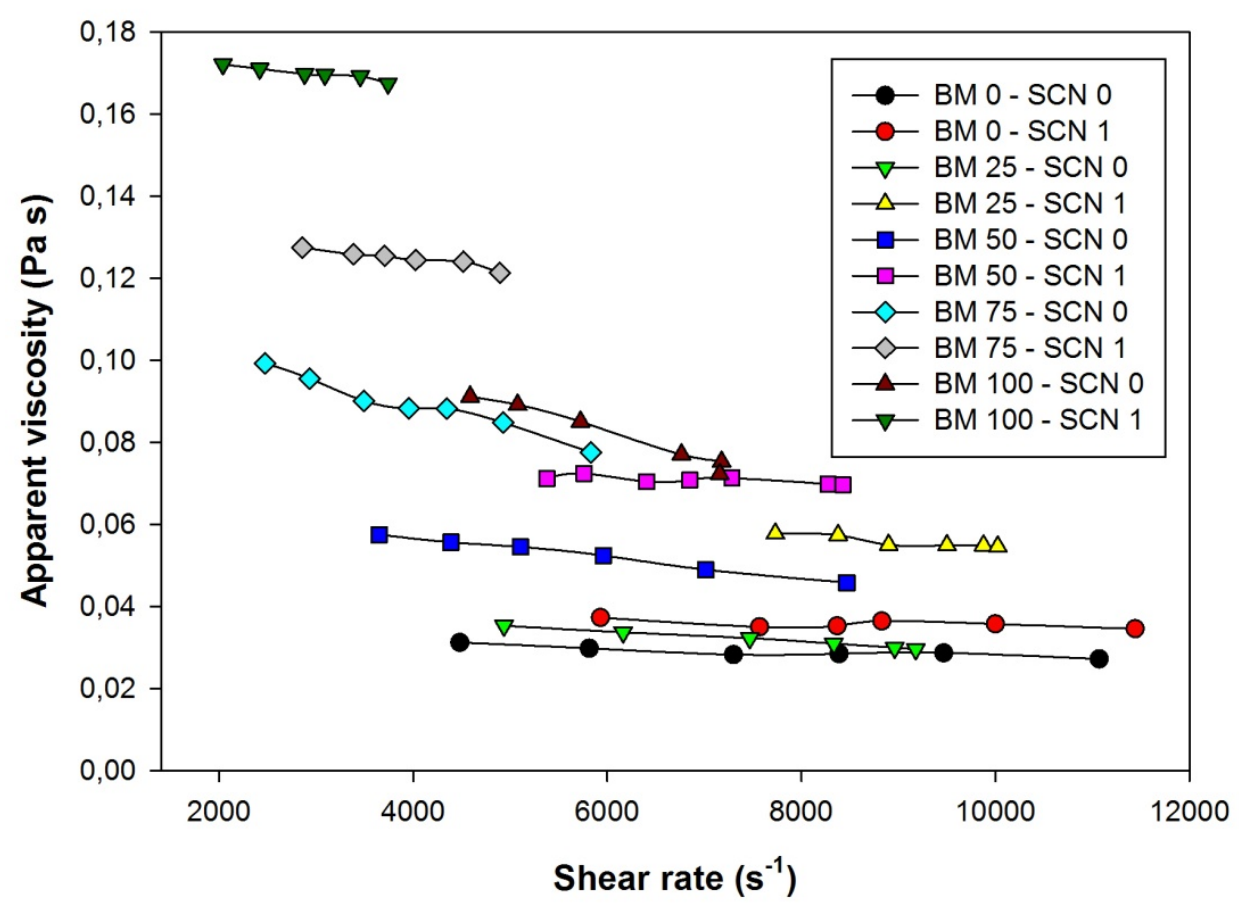

Figure 3. The flow curves of the yogurt samples

The milk blends and Sodium Caseinates (SCN) addition were abbreviated on the base of buffalo interest of the study as follows: BM 0, BM 25, BM 50, BM 75, BM 100, and SCN 0, SCN 1, respectively.

\subsection{Sensory Properties}

The sensory profile is demonstrated in Table 3. SCN addition increased the mean value of objective fattiness $(8.7>6.6)$ and viscosity $(8.5>5.4)$, as well as hedonic fattiness $(9.9>9.0)$ and viscosity $(10.0>7.0)$ and also the overall acceptability $(9.1>6.0)$ of the products. Main effects and interactions were found statistically significant only for the above mentioned variables.

Objective fattiness and viscosity showed an increasing trend along with buffalo milk concentrations $>50 \%$ independently of SCN addition (Figure 4). The latter produced significant effect at lower buffalo percentages whereas SCN addition increased the likeliness as compared to that free of SCN. 
Table 3. Mean values ( \pm SE below) of the sensory profile as tabulated by the main and interaction effects of milk blending and Sodium Caseinates (SCN) addition. Bold numbers indicate significant effects of SCN at 0.05 probability level

\begin{tabular}{|c|c|c|c|c|c|c|c|c|c|c|c|}
\hline \multirow[b]{2}{*}{ Treatment } & \multicolumn{6}{|c|}{ Objective variables } & \multicolumn{5}{|c|}{ Hedonic variables } \\
\hline & O_Odor & O_Whiteness & O_Acidity & O_Fatttiness & O_Viscosity & Acceptance & H_Odor $\mathbf{I}$ & H_Whiteness & H_Acidity & y H_Fattiness & H_Viscosity \\
\hline \multirow[t]{2}{*}{ SCN_0 } & 7.7 & 10 & 8.2 & 6.6 & 5.4 & 6 & 9.1 & 10.7 & 9.7 & 9 & 7 \\
\hline & 0.4 & 0.2 & 0.5 & 0.7 & 0.9 & 0.7 & 0.4 & 0.2 & 0.4 & 0.2 & 1 \\
\hline \multirow[t]{2}{*}{ SCN_1 } & 7.4 & 10.3 & 8.7 & 8.7 & 8.5 & 9.1 & 9.3 & 10.9 & 9.9 & 9.9 & 10 \\
\hline & 0.4 & 0.3 & 0.5 & 0.5 & 0.7 & 0.7 & 0.4 & 0.3 & 0.4 & 0.3 & 0.7 \\
\hline \multirow[t]{2}{*}{ BM_0 } & 7.6 & 9.7 & 7.2 & 6.8 & 4.1 & 4.4 & 8.8 & 11.3 & 9.8 & 9.3 & 4.7 \\
\hline & 0.6 & 0.7 & 0.4 & 0.3 & 1 & 0.7 & 0.8 & 0.3 & 0.5 & 0.8 & 1 \\
\hline \multirow[t]{2}{*}{ BM_25 } & 8.6 & 10.4 & 8.8 & 6.3 & 5.5 & 8.8 & 9.5 & 9.8 & 10 & 9.3 & 7.2 \\
\hline & 0.2 & 0.4 & 0.5 & 1.1 & 1 & 0.2 & 0.8 & 0.2 & 0.6 & 0.2 & 1.9 \\
\hline \multirow[t]{2}{*}{ BM_50 } & 8.2 & 10.5 & 8.5 & 6.9 & 6 & 7.7 & 8.9 & 10.9 & 10.3 & 9.1 & 8.7 \\
\hline & 0.6 & 0.1 & 0.4 & 0.6 & 1.4 & 0.7 & 0.8 & 0.5 & 0.8 & 0.4 & 0.6 \\
\hline \multirow[t]{2}{*}{ BM_75 } & 6.9 & 9.8 & 9.8 & 7.9 & 9 & 9.8 & 10.2 & 10.9 & 10.3 & 10.1 & 10.1 \\
\hline & 0.6 & 0.5 & 0.6 & 1.3 & 0.9 & 0.9 & 0.2 & 0.4 & 0.4 & 0.2 & 0.7 \\
\hline \multirow[t]{2}{*}{ BM_100 } & 6.5 & 10.5 & 7.9 & 10.4 & 10.1 & 9.6 & 8.5 & 11 & 8.7 & 9.6 & 11.8 \\
\hline & 0.5 & 0.2 & 1.2 & 0.5 & 0.7 & 1.4 & 0.2 & 0.5 & 0.7 & 0.5 & 0.6 \\
\hline
\end{tabular}

The milk blends and SCN addition were abbreviated on the base of buffalo interest of the study as follows: BM_0, BM_25, BM_50,BM_75, BM_100, and SCN_0, SCN_1, respectively.

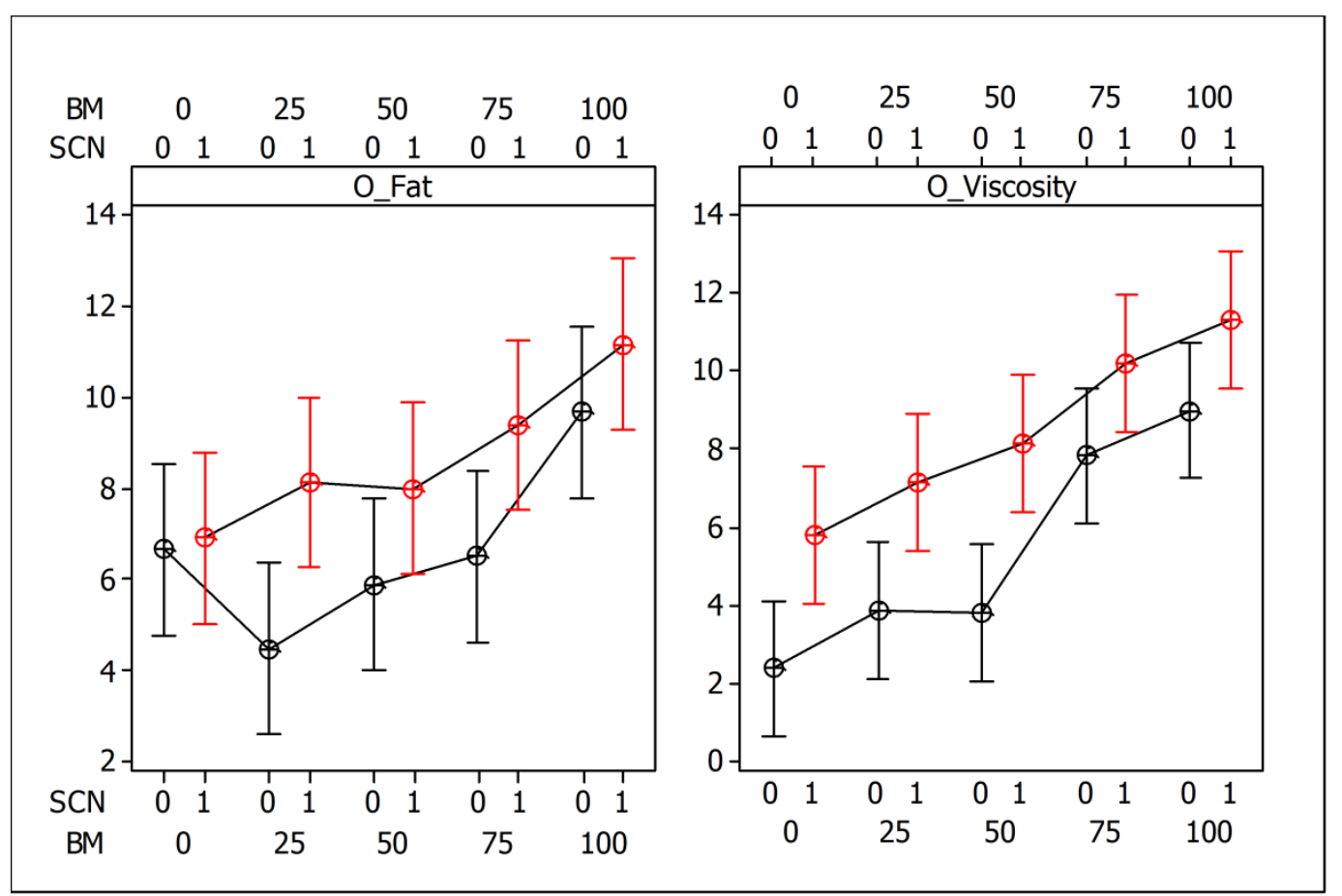

Figure 4. Mean changes of objective fattines and viscosity along with increasing buffalo concentration and the addition of Sodium Caseinates (SCN) or none. Vertical bars denote the $95 \%$ confidence intervals of means calculated from the error mean square of the analysis of variance 
The same trend pattern held for hedonic viscosity (Figure 5) showing striking lower acceptability at low buffalo milk compositions $(0-25 \%)$. Overall acceptability followed a higher hedonic trend with SCN addition particularly at buffalo milk levels $>50 \%$ while, at the same concentrations, blends free of SCN caused a lower and invariant shift (Figure 6). Generally, hedonic overall and attributes acceptability reached highest values in the range between 8-12 $\mathrm{cm}$ of the unstructured scale which is equivalent to 'adequate' perception.

Panelists scored yogurt samples with added SCN as more "fatty". This might be attributed to the deposition of caseins into the homogenized fat globules surface, which results in a false sense that the fat surface has been increased and so happens with the fattiness of yogurt samples. As it concerns the increasing buffalo concentration into the milk blend, results in increased fattiness due to its higher fat content.

The presence of added caseins into the milk system increased the hydrodynamic volume of the formed aggregates resulting in increased resistance to flow and thus viscosity. In accordance with the determination of the apparent viscosity of yogurt samples (Figure 3), the sensory evaluation showed an increase in viscosity with increasing casein concentration. The same stands for the increasing buffalo concentration, which results in protein and fat content increase of yogurt samples. Besides proteins (both caseins and denatured whey proteins), fat globules also increase the hydrodynamic volume of the aggregates. In homogenized milk, proteins (mainly caseins) are embedded into the fat globule membrane increasing this way the effective casein concentration (Tamine \& Robinson, 2007) and thus the resistance of the aggregates to flow. In agreement with the results of the present study, Hanif et al. (2012) reported that the sensory viscosity of buffalo milk yogurt is higher when compared to cow milk yogurt.

\subsection{Redundancy Analysis}

A stepwise forward selection of the most important factorial level effects in joint with the inter-set correlation between those and the first two axes produced from the redundancy analysis were the criteria to assess the significance of the analysis. Both axes explained $66.3 \%$ of the variation of the dependent set and $90.6 \%$ of the total variation considering both the variable sets. Buffalo concentrations at levels 0 and $100 \%$ were the most significant levels contributing $54.2 \%$ of variation for the two axes plus another $14.8 \%$ due to SCN addition totaling $68.0 \%$ (Table 4). SCN addition was responsible for the formation of axis 2 since it correlates strongly and positively $(0.801)$.

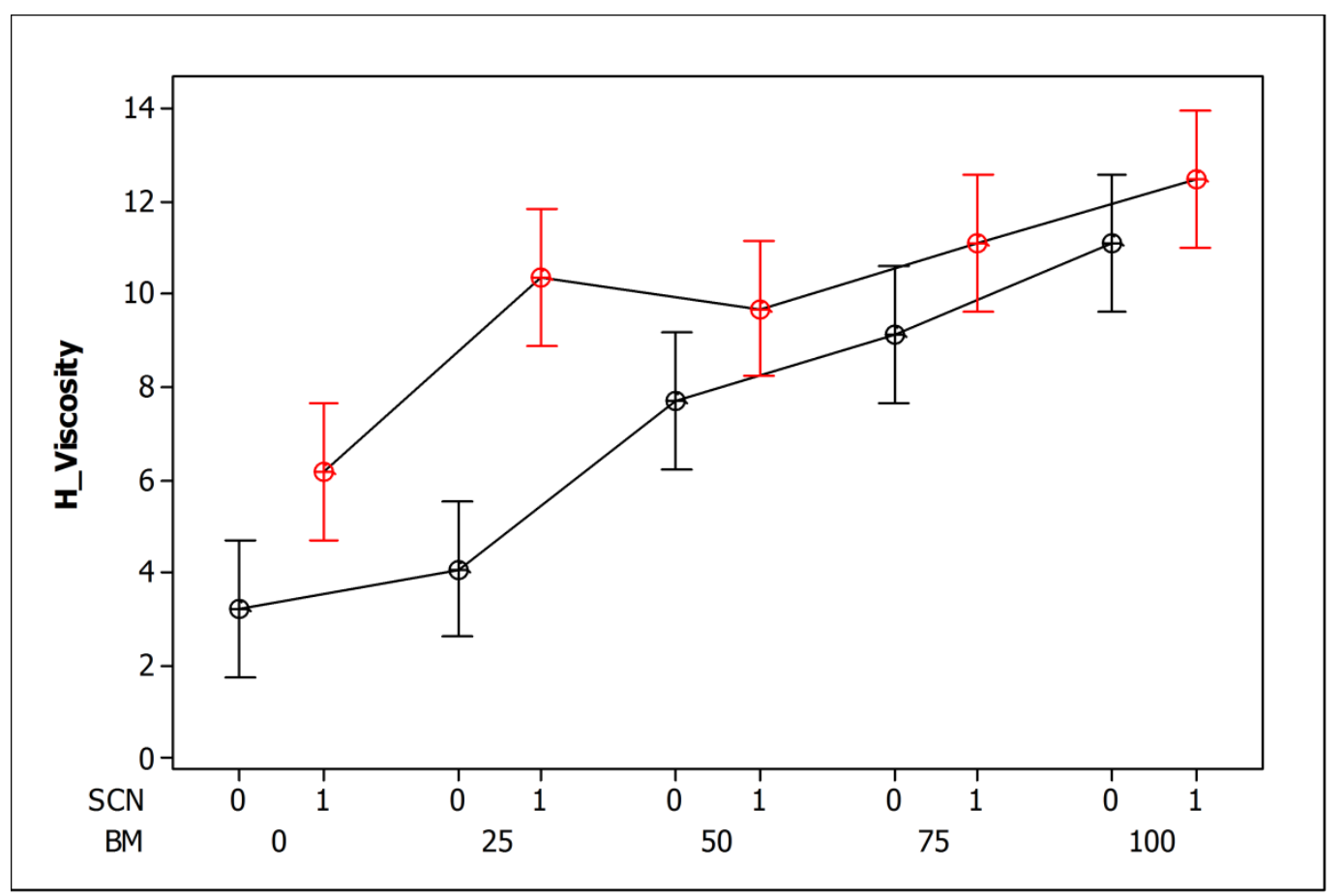

Figure 5. Mean change of hedonic viscosity along with increasing buffalo concentration and the addition of Sodium Caseinates $(\mathrm{SCN})$ or none. Vertical bars denote the $95 \%$ confidence intervals of means calculated from the error mean square of the analysis of variance 


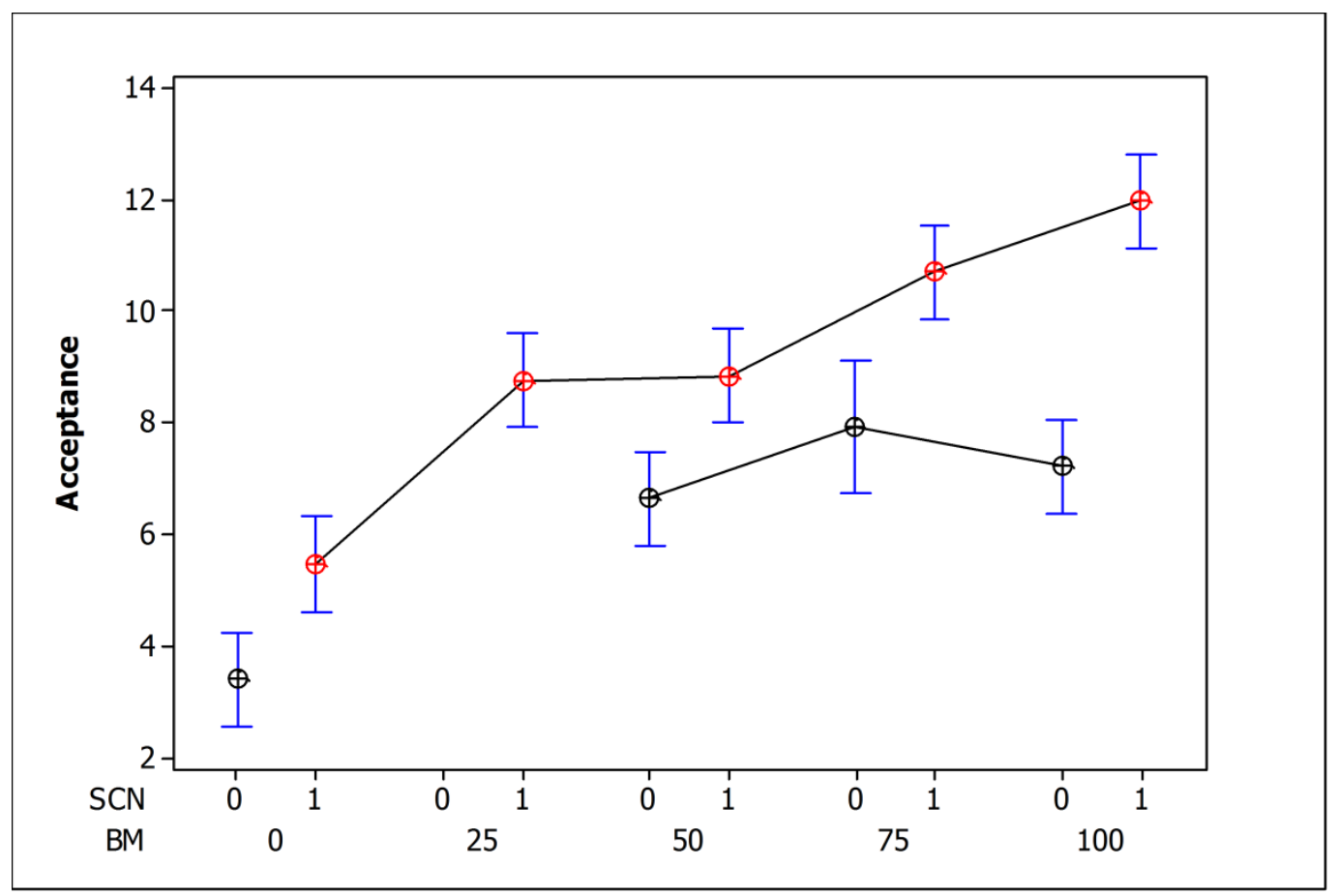

Figure 6. Mean changes of overall acceptability along with increasing buffalo concentration and the addition of Sodium Caseinates (SCN) or none. Vertical bars denote the $95 \%$ confidence intervals of means calculated from the error mean square of the analysis of variance

Table 4. Percentage contribution of main effects and inter-set correlation with the first two major axes for the attribute profile (objective sensory, rheological, colorimetric and chemical variables) and hedonic profile

\begin{tabular}{lllll}
\hline Attribute profile & contribution & significance & \multicolumn{2}{l}{ inter-set correlations } \\
\hline Sample & Fit $\%$ & $\mathrm{p}$ & AXIS 1 & AXIS 2 \\
BM_0 & 23.5 & 0.006 & -0.596 & 0.2648 \\
BM_25 & 7.8 & 0.172 & -0.3307 & 0.1967 \\
BM_75 & 8.9 & 0.168 & 0.3214 & -0.1923 \\
BM_100 & 30.7 & 0.006 & 0.6992 & -0.1504 \\
CSN_1 & 14.8 & 0.034 & 0.3782 & 0.801 \\
\hline Hedonic profile & contribution & significance & inter-set correlations \\
\hline Sample & Fit \% & p & AXIS 1 & AXIS 2 \\
BM_0 & 4.3 & 0.384 & -0.4618 & 0.2849 \\
BM_25 & 7.4 & 0.128 & -0.2878 & -0.4528 \\
BM_75 & 9.1 & 0.06 & 0.3619 & -0.3771 \\
BM_100 & 12.2 & 0.036 & 0.4743 & 0.4569 \\
SCN_1 & 10.2 & 0.048 & 0.5842 & -0.0978 \\
\hline
\end{tabular}

The milk blends and Sodium Caseinates (SCN) addition were abbreviated on the base of buffalo interest of the study as follows: BM_0, BM_25, BM_50, BM_75, BM_100, and SCN_0, SCN_1, respectively.

High and positive correlation coefficients with axis 1 were extracted for objective viscosity, L*, fat, acidity DM, NFDM and G' (Table 5). Tan $\delta$ and $\mathrm{b}^{*}$ correlated highly and negatively with axis 1 , and $\mathrm{n}$ positively and uniquely with axis 2 . Apparently, all the instrumental attributes, apart from $\mathrm{a}^{*}$, strongly contributed for the 
formation of axis 1 and 2 .

Table 5. Correlation coefficients of each response variable with the first two axes

\begin{tabular}{llllll}
\hline Attribute profile & AXIS 1 & AXIS 2 & Hedonic profile & AXIS 1 & AXIS 2 \\
\hline O_Odor & -0.5146 & 0.0843 & H_Odor & 0.084 & -0.4363 \\
O_Whiteness & 0.2014 & 0.1037 & H_Whiteness & 0.1841 & 0.4275 \\
O_Acidity & 0.2642 & 0.028 & H_Acidity & -0.1056 & -0.3359 \\
O_Fat & 0.7825 & 0.26 & H_Fat & 0.5456 & -0.1579 \\
O_Viscosity & 0.9237 & 0.2086 & H_Viscosity & 0.9009 & 0.0096 \\
L $^{*}$ & 0.9342 & -0.124 & & & \\
$\mathrm{a}^{*}$ & 0.0241 & -0.1278 & & & \\
$\mathrm{~b}^{*}$ & -0.9694 & -0.1203 & & & \\
Fat & 0.9058 & -0.412 & & & \\
Acidity & 0.9735 & -0.0977 & & & \\
DM & 0.9809 & -0.1708 & & & \\
NFDM & 0.9348 & 0.2642 & & & \\
$\mathrm{n}$ & -0.1415 & 0.8095 & & & \\
G' & 0.905 & -0.0745 & & & \\
tan $\delta$ & -0.8246 & -0.2329 & & & \\
\hline
\end{tabular}

The milk blends and Sodium Caseinates (SCN) addition were abbreviated on the base of buffalo interest of the study as follows: BM_0, BM_25, BM_50, BM_75, BM_100, and SCN_0, SCN_1, respectively; L*, a* and b*: the three components of color; DM: Dry Matter; NFDM: Non Fat Dry Matter; n: Flow behavior index; G': Elastic modulus; $\tan \delta$ : loss tangent.

Main effects and the variables under study, apart from hedonic, were plotted together to construct the triplot of Figure 7. Variables with longer arrows were more important in producing effects whereas those with same direction showed positive correlation and those with inverse direction showed negative correlation. The intensity of this correlation increased as the angle between the variables diminished. Two variables with angle direction of $90^{\circ}$ were totally not correlated. Samples positioned close to an arrow of a variable show strong relationship.

Two bundles of variables were formed on the right part of the graph and one on the left, showing high and positive correlation in each bundle (Figure 7). The right upper quartile consisted of samples and factorial levels with high buffalo milk concentrations enriched with casein, while the left hemisphere favored low buffalo levels or speaking inversely, high cow milk concentrations. More specifically, in the first bundle, high NFDM together with SCN addition defined higher intensities of objective fattiness and viscosity in samples nearly or fully presented with buffalo milk. This confirms the role of caseins in enhancing yogurt samples consistency, while in the presence of fat corroborate their active participation into the fat globule membrane increasing this way the mouth-fell of fattiness.

In the second bundle (Figure 7), DM, acidity and fat were all linked with higher values of G' and L* and best explained by $100 \%$ buffalo milk level effect whose position in the graph lying in the middle between samples $100 \_0$ and 100_1 seems to be unaffected by SCN addition. This statement is also supported by the findings in Table 2. According to these findings, it can be said that at $100 \%$ buffalo milk yogurt samples no protein supplementation is necessary. The buffalo milk proteins, can increase the buffering capacity of the system (Ahmad et al., 2008) (and thus the lactic acid concentration of yogurt), the elasticity of the gel and the light scattering of the samples (resulting in increased white color intensity). 


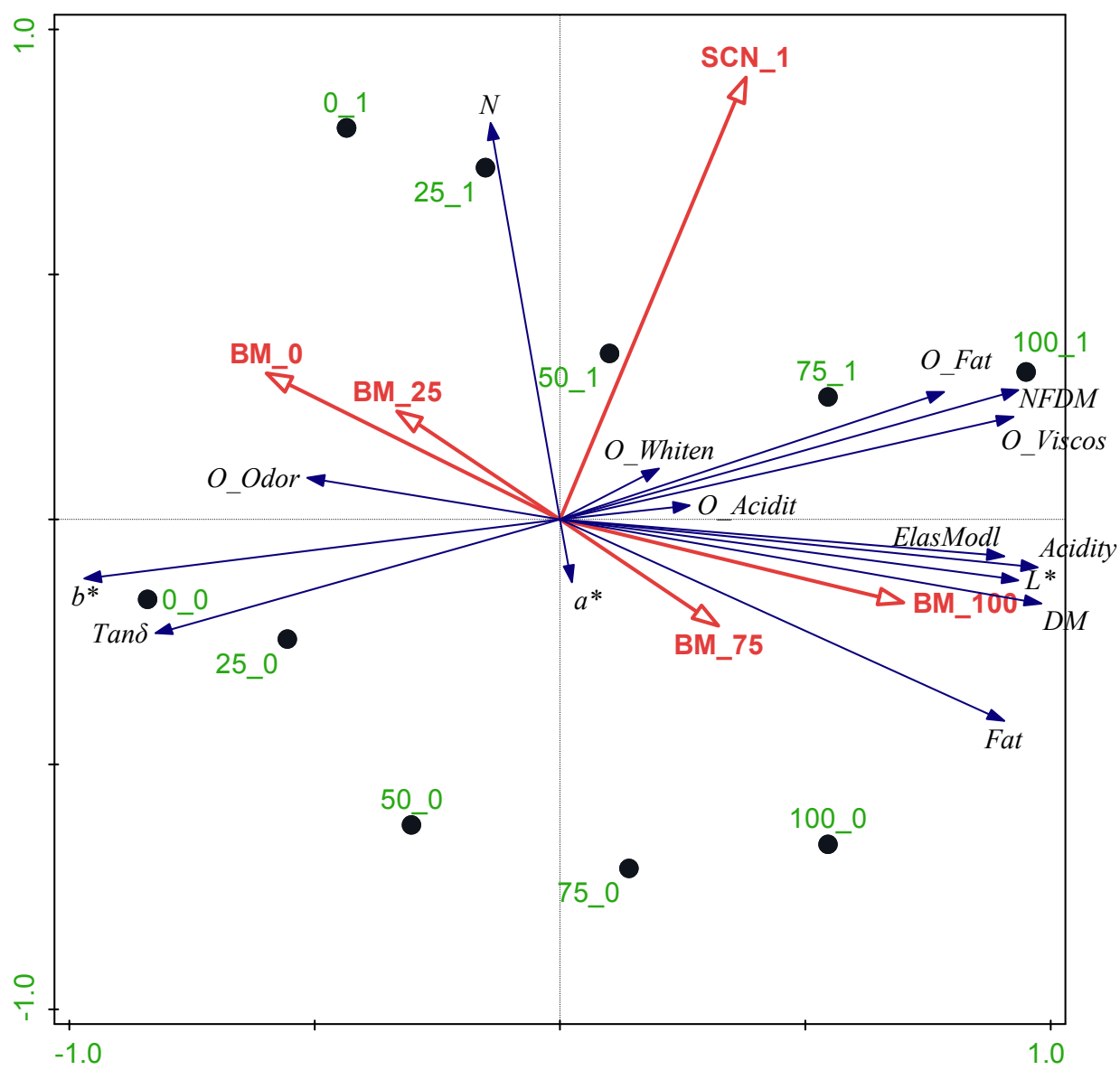

Figure 7. Triplot based on redundancy analysis of yogurt samples and sensory/physical/chemical profile with respect to main effects of milk mixture and addition of Sodium Caseinates (SCN). The lines for the two variable sets display the approximate correlation coefficients between and within these two sets of variables. The milk blends and SCN addition were abbreviated on the base of buffalo interest of the study as follows: BM_0, BM_25, BM_50, BM_75, BM_100, and SCN_0, SCN_1, respectively; L* and a*: the two components of color; DM: Dry Matter; NFDM: Non Fat Dry Matter; N: Flow behavior index; ElasModl: Elastic modulus; Tan $\delta$ : loss tangent; The capital letter O, denote objective sensory properties

Both bundles correlated strongly and negatively with the left bundle, in which, objective odor, $\mathrm{b}^{*}$ and $\tan \delta$ were influenced by buffalo milk levels 0 and $25 \%$ in the proximity of samples $0 \_0$ and 25_0, free of SCN. In the absence of SCN and at low buffalo milk concentration, yogurt samples exhibited a more liquid-like behavior due to the low protein concentration. The presence of cow milk at high percentages results in samples with intensive odor (probably attributed to the characteristic flavor of cow milk) and a more yellow color intensity (due to the increased concentration of carotenoids).

The SCN addition and $\mathrm{n}$ represented the significance of axis 2 and consequently correlated strongly and positively in samples with low buffalo milk concentrations (0_1 and 25_1), confirming the role of buffalo milk fat in reducing the Newtonian behavior of yogurt samples and that of the caseins in exhibiting to yogurt samples a tendency toward Newtonian behavior.

With regard to hedonic sensory profile, the main factorial effects were best explained by $100 \%$ buffalo milk enrichment $(\mathrm{p}=0.036)$ and less by $75 \%(\mathrm{p}=0.06)$ and by $\mathrm{SCN}$ addition $(\mathrm{p}=0.048)$ totaling $31.5 \%$ of the total variation (Table 3). Variation in both axes was explained by $77.7 \%$ from the whole data. Hedonic viscosity was the most effective variable to form axis 1 correlating strongly with it $(0.90)$ and secondarily hedonic fattiness (0.55).

A global view hedonic variables and main effects are provided by the triplot in Figure 8. SCN addition increased efficiently the likeliness of viscosity and fattiness because all manifest strong positive correlations in samples 
with high buffalo milk concentration (75_1 and 100_1). Whiteness increased at $100 \%$ buffalo milk level irrespectively of SCN addition, while hedonic acidity and odor were more intensive at buffalo levels 25 and $75 \%$ without any SCN effect.

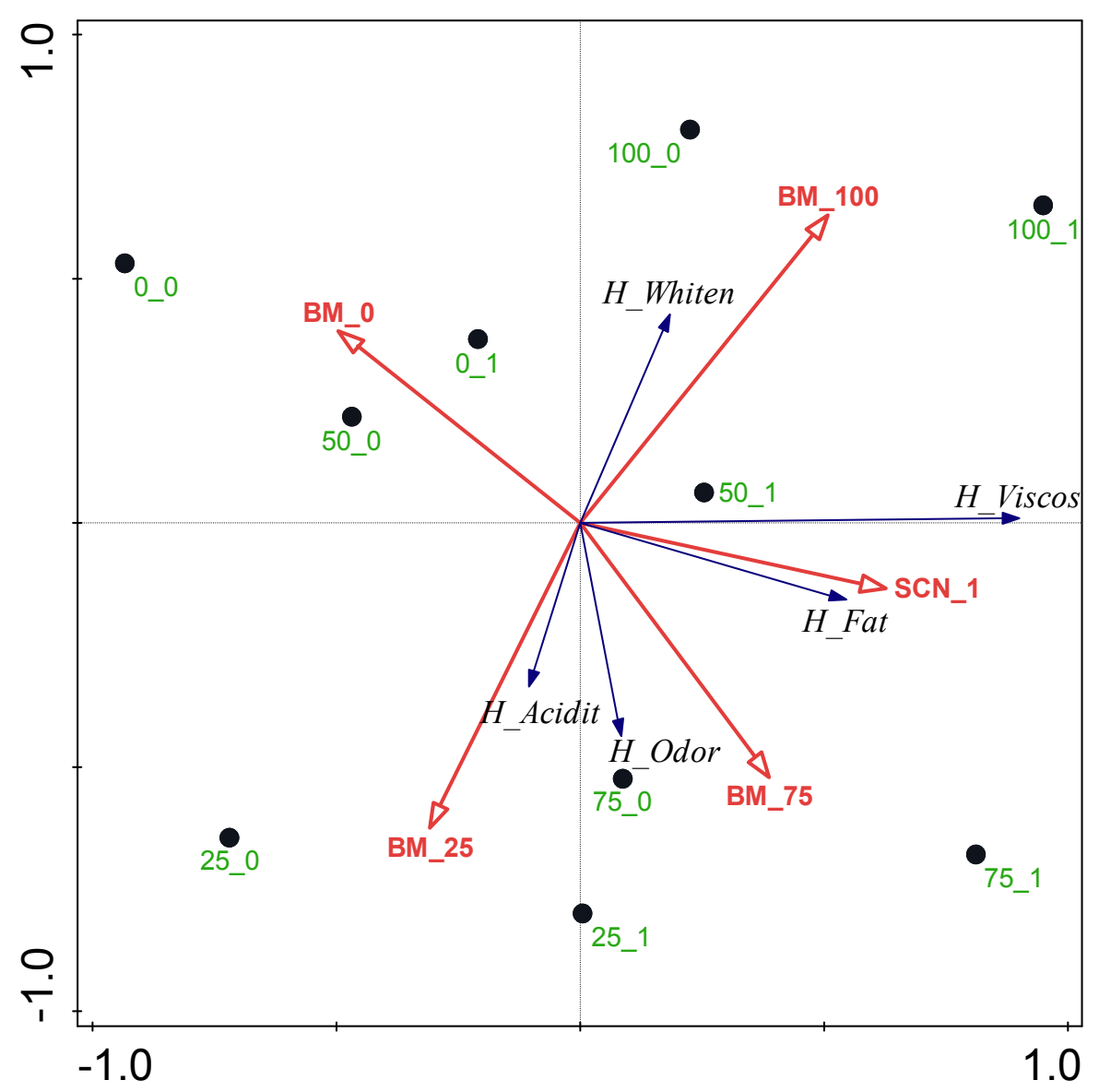

Figure 8. Triplot based on redundancy analysis of yogurt samples and hedonic profile with respect to main effects of milk mixture and addition of Sodium Caseinates (SCN). The lines for the two variable sets display the approximate correlation coefficients between and within these two sets of variables

The milk blends and SCN addition were abbreviated on the base of buffalo interest of the study as follows: BM_0, BM_25, BM_50, BM_75, BM_100, and SCN_0, SCN_1, respectively.

\section{Conclusions}

Milk blending affected significantly all the instrumental variables apart from $\mathrm{a}^{*}$ and so happened but sparsely with the interactive effects between milk mixture and SCN addition.

SCN addition increased the brightness and reduced the yellow color intensity of yogurt samples. The elasticity of the protein matrix as well as the apparent and the sensory viscosity of stirred yogurt increased in the presence of SCN and the samples showed a tendency towards Newtonian behavior.

Redundancy analysis appeared evidently a strong tool to elucidate the physicochemical, rheological and sensory profile of a stirred yogurt product. Tan $\delta$ and $\mathrm{b}^{*}$ were indicative of high cow milk concentrations and the rest of attributes fashion with high buffalo milk concentrations, apart from $\mathrm{n}$ which favored samples with high cow milk enrichment and SCN addition.

Panelists scored sufficiently acceptable a stirred yogurt rich in buffalo milk concentration (75-100\%) and low in cow milk (0-25\%), enriched with SCN, with texture perceived as adequate fatty and viscous.

\section{Acknowledgments}

The authors wish to thanks Mr Kleonas Tsakmakidis (Hellenic Protein S.A.) for the supply of the SCN. 


\section{References}

Ahmad, S., Gaucher, I., Rousseau, F., Beaucher, E., Piot, M., Gronget, J. F., \& Gaucheron, F. (2008). Effects of acidification on physico-chemical characteristics of buffalo milk: A comparison with cows' milk. Food Chemistry, 106, 11-17. http://dx.doi.org/10.1016/j.foodchem.2007.04.021

AOAC. (2002). Official Methods of Analysis, (17th Ed). Gaithersburg, Maryland: Association of Official Analytical Chemists.

Chandan, R. C. (2006). History and consumption trends. In R. C. Chandan (Ed.), Manufacturing yogurt and fermented milks (pp. 3-16). Oxford, Iowa, Victoria: Blackwell Publishing. http://dx.doi.org/10.1002/9780470277812

Cochran, W. G., \& Cox, G. M. (1957). Experimental designs (2nd ed.). New York: Wiley.

Dimitreli, G., \& Thomareis, A. S. (2004). Effect of temperature and chemical composition on processed cheese apparent viscosity. Journal of Food Engineering, 64, 265-271. http://dx.doi.org/10.1016/j.jfoodeng.2008.10.008

Dimitreli, G., Petridis, D., Akakiadou, P., \& Chrysalidou, S. (2014). Effect of protein supplementation, fat globule size and storage time on the rheological and sensory properties of buffalo milk stirred yogurt. Journal of Food Research, 3, 31-44. http://dx.doi.org/10.5539/jfr.v3n5p31

Fox, P. F., Guinee, T. P., Cogan, T. M., \& McSweeney, P. L. H. (2000). Fundamentals of Cheese Science. Gaithersburg, Maryland: Aspen Publishers, Inc.

Hanif, M. S., Zahoor, T., Iqbal, Z., Ihsan-ul-haq, \& Arif, A. M. (2012). Effect of storage on the rhological and sensory characteristics of cow and buffalo milk yogurt. Pakistan Journal of Food Sciences, 22(2), 61-70.

IDF. (1991). Yogurt Products - Determination of Total Solids (Gravimetric Method). IDF Standard 151. Brussels: International Dairy Federation.

ISO. (1976). Milk-Determination of fat content-(Boutyrometric routine method). ISO Standard 2446. Geneva: International Standards Organization.

Khedkar, C. D., Khedkar, G. D., Patil, M. R., \& Kalyankar, S. D. (2003). Encyclopedia of Food Sciences \& nutrition (2nd ed.) (pp. 705-709). Maryland: Academic Press. http://dx.doi.org/10.1016/B0-12-227055-X/00134-6

Lucey, J. A. (2004a). Cultured dairy products: an overview of their gelation and texture properties. International Journal of Dairy Technology, 57, 77-84. http://dx.doi.org/10.1111/j.1471-0307.2004.00142.x

Lucey, J. A. (2004b). Formation, structural properties and rheology of acid-coagulated milk gels. In P. F. Fox, P. L. H. McSweeney, T. M. Cogan \&T. P. Guinee (Eds), Cheese: Chemistry, physics and microbiology, Third edition- Volume I: General aspects (pp. 105-122). Amsterdam, Boston, Heidelberg, London, New York, Oxford, Paris, San Diego, San Francisco, Singapore, Sydney, Tokyo: Elsevier Ltd

Lucey, J. A., \& Singh, H. (1998). Formation and physical properties of acid milk gels: a review. Food Research International, 30, 529-542. http://dx.doi.org/10.1016/S0963-9969(98)00015-5

Masud, T., Khalid, S., Maqsood, S., \& Bilal, A. (2010). Preservation of raw buffalo's milk by the activation of lactoperoxidase system and its effect on yogurt preparation. Journal of Food Processing and Preservation, 34, 241-254. http://dx.doi.org/10.1111/j.1745-4549.2008.00337.x

Petridis, D., Dimitreli, G., Chrysalidou, S., \& Akakiadou, P. (2013). Optimization of the rheological and sensory properties of stirred yogurt as affected by chemical composition and heat treatment of buffalo milk. Journal of Food Research, 2, 55-70. http://dx.doi.org/10.5539/jfr.v2n6p55

Robinson, R. K., Lucey, J. A., \& Tamine, A. Y. (2006). Manufacture of yoghurt. In A. Y. Tamine (Ed.), Fermented milks (pp. 53-75). Oxford, Iowa, Victoria: Blackwell Science Ltd. http://dx.doi.org/10.1002/9780470995501.ch3

Simanca, M. M., Andrade, R. D., \& Arteage, M. R. (2013). Effect of bran wheat on the physico-chemical and sensory properties of buffalo mil yogurt. Información Tecnológica, 24(1), 79-86. http://dx.doi.org/10.4067/S0718-07642013000100010

Sodini, I., Remeuf, F., Haddad, S., \& Corrieu, G. (2004). The relative effect of milk base starter culture and process on yogurt texture: A review. Critical Reviews in Food Science and Nutrition, 44, 113-137. http://dx.doi.org/10.1030/10408690490424793 
Tamine, A. Y., \& Robinson, R. K. (2007). Tamine and Robinson's yogurt. Science and technology (3rd ed.). Boca Raton, Boston, New York, Washington, DC: CRC Press.

ter Braak, C. J .F., \& Smilauer, P. (2012). Canoco reference manual and user's guide: software for ordination (version 5.0). Microcomputer Power, Ithaca. NY: Biometrics.

Walstra, P., Wouters, J. T. M., \& Geurts, T. J. (2006). Dairy Science and Technology (2nd ed.). Boca Raton: Taylor \& Francis, CRC Press.

Xu, Z., \& Raphaelides, S. N. (1998). Flow behavior of concentrated starch dispersions using a tube rheometer of novel design. Journal of Texture Studies, 29, 1-13. http://dx.doi.org/10.1111/j.1745-4603.1998.tb00150.x

\section{Copyrights}

Copyright for this article is retained by the author(s), with first publication rights granted to the journal.

This is an open-access article distributed under the terms and conditions of the Creative Commons Attribution license (http://creativecommons.org/licenses/by/3.0/). 